\title{
Detection and molecular characterization of uncommon rotavirus group A genotype G12 among hospitalized children in Chennai
}

\author{
Ponnambalam Arun ${ }^{1,3}$, Kaveri Krishnasami ${ }^{1}$ Palani Gunasekeran ${ }^{1}$, Gracy Fathima ${ }^{1}$, \\ Vidya Padmanabhan 2,3 \\ ${ }^{1}$ Department of Virology, King Institute of Preventive Medicine and Research, Guindy, Chennai; ${ }^{2}$ Department of Microbiology, \\ D.G.Vaishnav College,Chennai; ${ }^{3}$ Bharathiar University, Coimbatore, India. E-mail: arunpatchai@yahoo.co.in \\ Received: 14th November 2017, Revised: 16th April 2018, Accepted: 17th April 2018
}

\begin{abstract}
SUMMARY: Arun P, Krishnasami K, Gunasekeran P, Fathima G, Padmanabhan V. Detection and molecular characterization of uncommon rotavirus group A genotype G12 among hospitalized children in Chennai. Turk J Pediatr 2019; 61: 209-216.

Human group A (RVAs) possess genetic diversity and often newer RVA strains have been reported frequently with different $\mathrm{G}$ and $\mathrm{P}$ combinations worldwide. As the disease burden is more common in low income countries including India, monitoring and detection of the circulating strains of rotavirus needs to be monitored to understand the genetic diversity of the strains which evolve over time. This study was an attempt to provide data on rotavirus gastroenteritis prevalence in and around Chennai Tamilnadu-South India during the pre-vaccination era.

Stool samples were collected and tested from 401 children less than five years of age admitted to hospitals with acute gastroenteritis. The samples were subjected to amplification for VP7 and VP4 genes by using consensus primers, followed by semi-nested type-specific multiplex PCR. Phylogenetic analysis of VP7 genes of G12 were carried out and the variations between strains isolated globally were documented.
\end{abstract}

Rotavirus was detected in $167(41.64 \%)$ samples and five were found to be the uncommon G12P[6] genotype (2.99\%) tested by RT-PCR followed by G1P [8], G9P [4], G9 with P untypable and G3P [8] and combinations of G2G9P[6] and G9G2P[11] with few strains untypable. In this study we highlight the occurrence of uncommon G12P[6] strain of rotavirus infection in the community.

Since rotavirus is transmitted through oral-fecal route and monitoring of environmental cleanliness is mandatory to cease the spread of this deadliest viral agent to achieve our MDG-IV. Covering single genotype will have to be modified with respect to the circulating stains.

Key words: G12, diarrhea, gastroenteritis, RT-PCR, rotavirus, MDG-IV.

Rotaviruses are $70 \mathrm{~nm}$ icosahedral, nonenveloped, double-stranded RNA viruses that belong to the family Reoviridae. The virus is characterized by its three-layer capsid, an outer and an inner capsid and an internal shell that surrounds the 11-segment double-stranded RNA genome. The outer capsid is made of two proteins, VP4, also named "P protein", and VP7, also known as the "G protein", which define the "P" and "G" serotypes of the virus, respectively.
Both are key neutralization determinants on the surface of the virion. The inner capsid is made of the VP6 protein, the most abundant and immunogenic protein in the virion. NSP4 is a viral enterotoxin which induces diarrhea and was the first viral enterotoxin discovered. ${ }^{1}$

Rotavirus is the most common cause of severe gastroenteritis in infants and young children worldwide and ranks second in causing mortality among children under five years of 
age. The clinical spectrum of rotavirus illness ranges from mild, watery diarrhea of limited duration to severe diarrhea with vomiting and fever that can result in dehydration with shock, electrolyte imbalance and death. It has an incubation period of 1-3 days, the illness often begins abruptly, and vomiting often precedes the onset of diarrhea. The gastrointestinal symptoms generally resolves in 3-7 days and up to one-third of patients have a temperature of $>39^{\circ} \mathrm{C}$. Severe, dehydrating rotavirus infection occurs primarily among unvaccinated children aged 3-35 months. Adults can also be infected, though disease tends to be milder. ${ }^{2}$

Globally human rotavirus A is responsible for around 2 million hospitalizations ${ }^{3}$ and 0.2 million deaths annually. ${ }^{4}$ Mortality is the greatest in south, south-eastern Asia and subSaharan Africa, with almost 100,000 deaths each year in India alone, and more than 200,000 in African countries. ${ }^{5}$ Rotavirus immunization among the Asian population would avert about 110,000 deaths, 1.4 million hospitalizations and 7.7 million hospital outpatient visits. ${ }^{6}$

There has been considerable year-to-year variation among the circulating G-P types, wherein G1P[8] was predominant in 1998 (42\% of samples) and in 2002 (26\%), G2P[4] was the strain that was most frequently detected in 2000 (26\% of samples). G12 strain which was first isolated and reported in the Philippines during 1990 was serologically characterized and was not in circulation until 2002.7-9 In 2002, G12 strains were reported from eastern India, responsible for 25 out of 147 rotavirus infections making it the third most common genotype after G1 and G2.10

Global reviews of the main $G$ and $P$ type combinations encountered in human infections have been identified as G1P1A[8] (where P1A is the serotype designation and $\mathrm{P}[8]$ is the genotypic designation), G2P1B[4], G3P1A[8], and $\mathrm{G} 4 \mathrm{P} 1 \mathrm{~A}[8]^{11}$ are the most frequent strains, however other $\mathrm{G}$ types have been predominant in various geographical settings. The other strains were also detected in mammals, namely, G5 (found in pigs and horses) in Brazil12, G8 (found in cattle) in various parts of Africa ${ }^{13}$, and G10 (found in cattle) in India. ${ }^{14}$

However a number of other genotypes have also been detected in significant numbers from time to time ${ }^{15}$ and it should be considered that factors such as vaccine pressure can also lead to the changing patterns in diversity of circulating rotavirus. ${ }^{16}$

The aim of the current study was to analyze the circulation and prevalence of human rotavirus genotypes in and around Chennai among hospitalized children under five years of age due to gastroenteritis.

\section{Material and Methods}

\section{Study Population}

The present study was carried out among hospitalized 401 pediatric subjects, from in and around Chennai, aged 0-5 years suffering from acute gastroenteritis as per case definition and as suggested by physicians. The study period was from January 2013 to December 2014.

Samples were collected from children with acute watery diarrhea. Diarrhea was defined the occurrence of three or more loose, liquid, or watery stools or at least one bloody loose stool in a 24 -h period. ${ }^{17}$ Stool samples were collected within 48 hours of onset of symptoms.

Institutional ethical clearance was obtained. Written informed consent was obtained from parents of those children who were included in the study.

Children between 1-5 years of age who were hospitalized with suspected viral gastroenteritis as per case definition were included in this study. Neonates and children who had developed dysentery, diarrhea of more than 14 days, or symptoms of diarrhea after hospitalization due to any other cause were excluded from this study. None of the cases were vaccinated for rotavirus according to the history given by parents or guardian.

\section{ELISA}

The presence of rotavirus antigen was detected by EIA- (Rotaclone, Premier, Meridian Biosciences Inc., USA) in the Department of Virology, King Institute of Preventive Medicine and Research, as per the manufactures instructions.

\section{Viral RNA extraction and genotyping}

A $10 \%(\mathrm{v} / \mathrm{v})$ suspension of antigen-positive stool samples was prepared in phosphatebuffered saline (PBS). The fecal suspension was vortexed and centrifuged at 3,500 $\mathrm{g}$ for 15 min at $4^{\circ} \mathrm{C}$. By using QIA amp viral RNA 
Mini Kit, Qiagen GmbH, and Hilden, Germany, - $140 \mu$ l of the supernatant was then used for RNA extraction according to manufacturer's instructions. ${ }^{18}$

\section{$G$ and $P$ genotyping}

Extraction of RNA from samples that tested positive for rotaviral antigen were subjected to RT-PCR for detecting VP6 using miniviral RNA kit (QIAgenGmbhHildem,Germany) which yielded a PCR product of $336 \mathrm{bp}$. Before addition of RNA to RT-PCR mix, sample RNA was subjected to denaturation at $95^{\circ} \mathrm{C}$ for five minutes followed by immediate incubation in ice for 3 minutes to separate double strand and this single strand was used as a template for RTPCR to amplify VP6 gene using the Invitrogen one step RT-PCR kit. Those that were positive for VP6 were subjected to genotyping using semi-nested primers for RT-PCR to amplify VP4 and VP7 for G and P genotyping using multiplex PCR primers as described. ${ }^{19}$ In the first round PCR $881 \mathrm{bp}$ region of VP7 gene was identified using VP7-F and VP7-R primers, then the first round product was used for the second round along with a mixture of VP-7 $\mathrm{F}$ and specific reverse primers towards G1,G2,G3,G4,G8,G9 G10 and G12 genotypes. ${ }^{20}$ For P genotyping a region of $876 \mathrm{bp}$ of VP4 was amplified using con 2 and con 3 primers and the first round was used as a template for the second round where con3 was used as VP4-F and mixture of $\mathrm{P}[4], \mathrm{P}[6], \mathrm{P}[8], \mathrm{P}[9], \mathrm{P}[10]$ and $\mathrm{P}[11]^{21}$ were used as VP4-R primers.

The amplified product was then analyzed on $1.5 \%$ agarose gel. Samples which did not react to any of $\mathrm{G}$ or $\mathrm{P}$ genotype specific primers

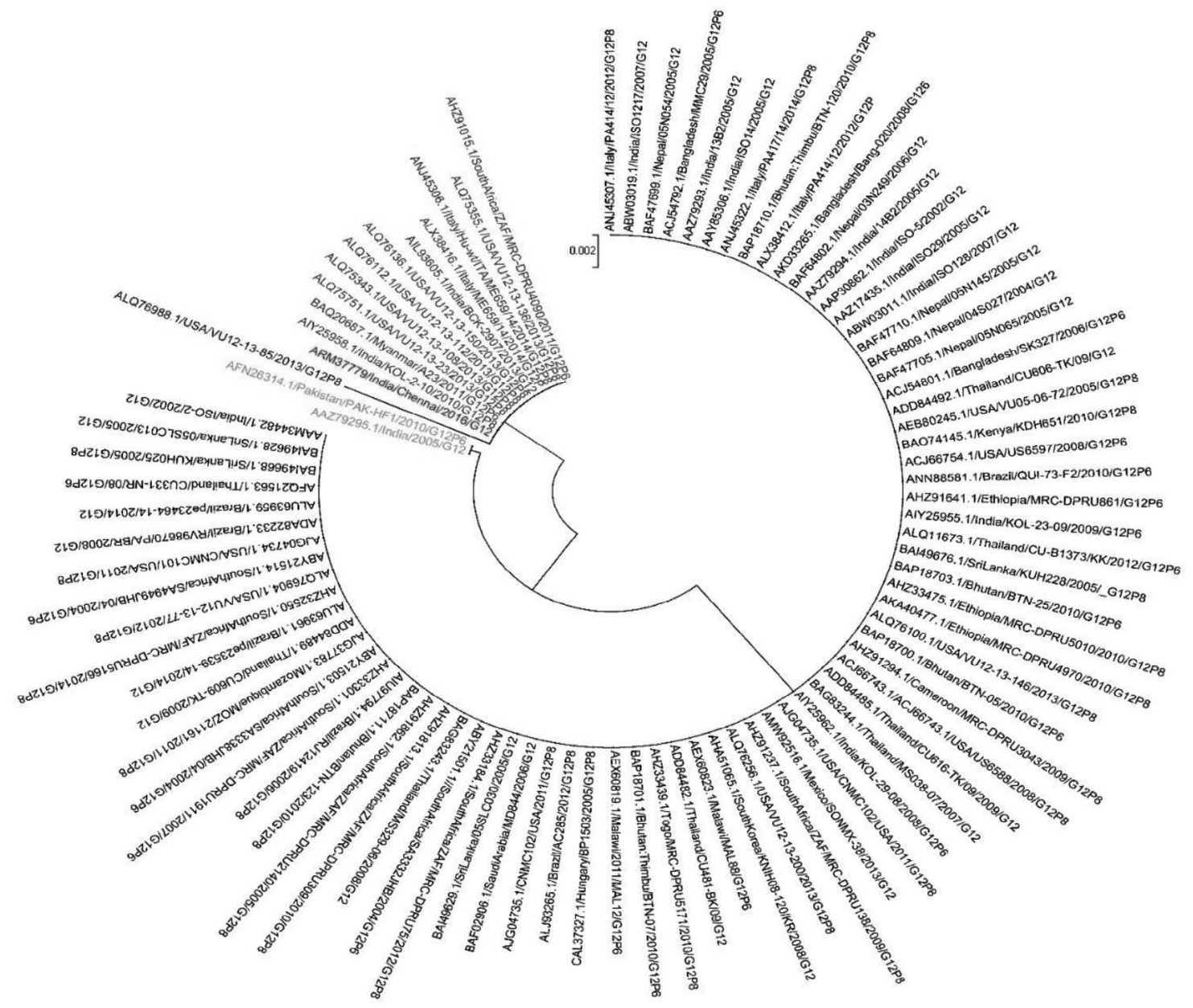

Fig. 1. Phylogenetic analysis of G12 Chennai strain and its related strains. 
BAI49629.1/SriLanka/05SLC030/2005/G12 AHZ33184.1/SouthAfrica/ZAF/MRC-DPRU75/2012/G12P8 ABY21501.1//SouthAfrica/SA3332JHB/2004/G12P6 BAG83243.1/Thail and/MS329-06/2008/G12 AHZ91813.1/SouthAfrica/ZAF/MRC-DPRU309/2010/G12P8 AHZ91862.1/SouthAfrica/ZAF/MRC-DPRU2140/2005/G12P8 BAP18711.1/Bhutan/BTN-123/2010/G12P8 AIU97794.1/Brazil/RJ12419/2006/G12P8 AHZ33301.1/SouthAfrica/ZAF/MRC-DPRU1911/2007/G12P6 ABY21503.1/SouthAfrica/SA3338JHB/04/2004/G12P6 AJG37783.1/Mozambique/MOZ/21161/2011/G12P8 ADD84489.1/Thailand/CU609-TK/2009/G12 ALU63961.1/Brazil/pe23539-14/2014/G12 AHZ32550.1/SouthAfrica/ZAF/MRC-DPRU5166/2014/G12P8 ALQ76904.1/USA/VU12-13-77/2012/G12P8 ABY21514.1/SouthAfrica/SA4949JHB/04/2004/G12P6 AJG04734.1/USA/CNMC101/USA/2011/G12P8 AAZ79295.1/India/2005/G12

AFN26314.1/Pakistan/PAK-HF1/2010/G12P6 ADA82233.1/Brazil/RV98670/PA/BR/2008/G12 ALU63959.1/Brazil/pe23464-14/2014/G12 AF021563.1/Thailand/CU331-NR/08/G12P6 BAI49668.1/SriLanka/KUHO25/2005/G12P8 BAI49628.1/SriLanka/05SLCO13/2005/G12 AAM34482.1/India/ISO-2/2002/G12 AIY25958.1/India/KOL-2-10/2010/G12P8 BAQ20687.1/Myanmar/A23/2011/G12P6 ALQ75751.1/USA/VU12-13-23/2013/G12P8 AL075343.1/USA/VU12-13-108/2013/G12P8 ALQ76112.1/USA/VU12-13-112/2013/G12P8 ALQ76136.1/USA/VU12-13-150/2013/G12P8 AIL93605.1/India/BCK-2907/2013/G12 ALX38416.1/Italy/ME659/14/2014/G12P ANJ45306.1/Italy/Hu-wt/ITA/ME659/14/2014/G12P8 AL076988.1/USA/VU12-13-85/2013/G12P8 AL075355.1/USA/VU12-13-136/2013/G12P8 AHZ91015.1/SouthAfrica/ZAF/MRC-DPRU4090/2011/G12P6 ARM37779/India/Chennai/2016/G12

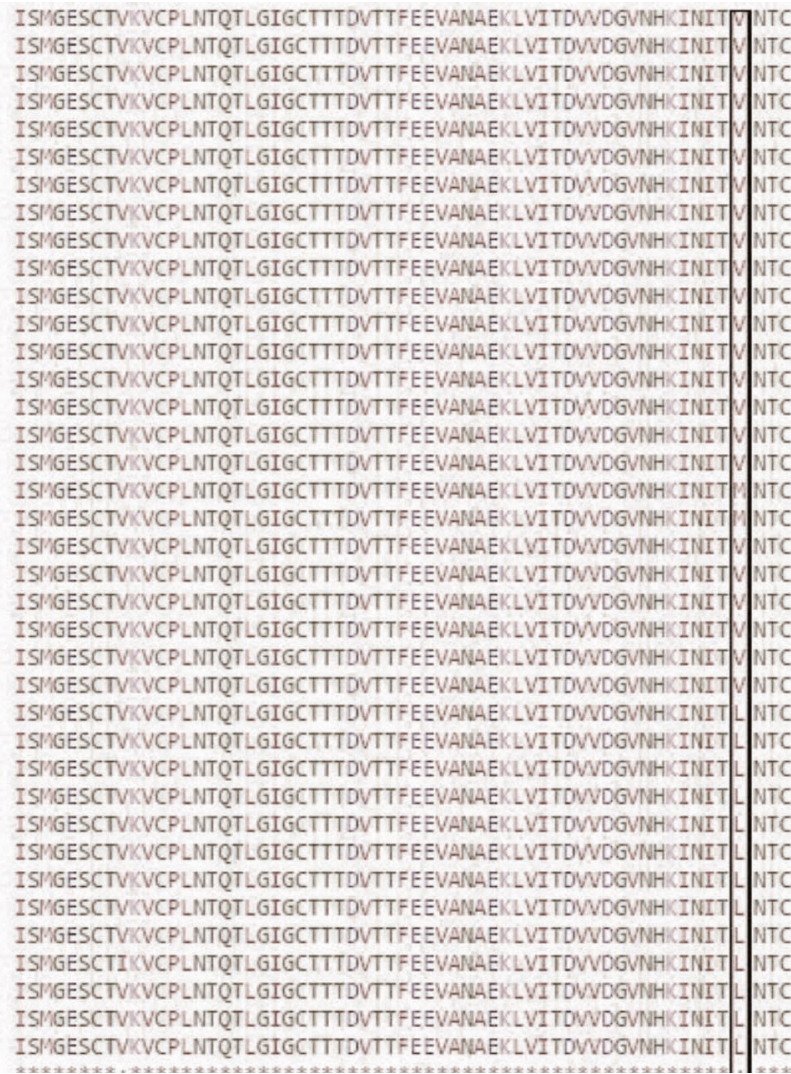

ISMGESCTVIVCPLNTQTLGIGCTTTDVTTFEEVANAEKLVITOWDGVNHICINI

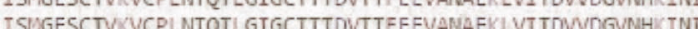
ISMGESCTVIVCPLNTQTLGIGCTTTDVTTFEEVANAEKLVITOWVDGVNHICINI ISNGESCTVIVCPLNTOTLGIGCTTTDVTTFEEVANAEKLVITOWDGVNHKINI ISMGESCTVIVCPLNTQTLGIGCTTTDVTTFEEVANAEKLLITOWDGVNHKINI ISGESCTVIVCPLNTOTLGIGCTTTDVTTFEEVANAEKLVITDVVDGVNHICINI ISMGESCTVKVCPLNTQTLGIGCTTTDVTTFEEVARAEKLVI TDVVDGVNHICINI WESCTVVCPLNTOTLGIGCTTTDVTTFEEVANAEKCLITOWDOGVNHIINI ISIGESCTVKVCPLNTOTLGIGCTTTDVTTFEEVANAAEKLVITOWVGVNHKIN ISUGESCTUUCPLT ISMGESCTVIVCPLNTOTLGIGCTTTDVTTFEEVANAEKLVITONDGVNHICINI ISMGESCTVIVCPLNTQTLGIGCTTTDVTTFEEVANAEKLVITOWDGVNHICINI ISWGESCTVUCPLNTOTLGIGCTTTDVTTFEEVANAEKLVTTDNDOVNHCTNI ISWGESCTVIVCPLNTOTLGIGCTTTDVTTFEEVANAEKLVITDWVDVVNHCINI ISMGESCTVIVCPLNTQTLGIGCTTTDVTTFEEVANAEKLVITOWDGVNHICINI ISIMGESCTVKVCPLNTQTLGIGCTTTDVTTFEEVANAEKLVI TOWDGVNHICINI

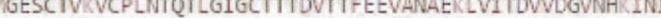
ISMGESCTVIVCPLNTOTLGIGCTTTDVTTFEEVANAEKLVITOVVDGVNH INI ISIGESCTVIVCPLNTQTLGIGCTTTDVTTFEEVANAEKLVITDWVGVNHICINI

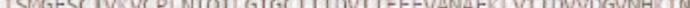
ISWGESCTVIVCPLNTQTLGIGCTTTDVTTFEEVANAEKLVITOWDGVNHKIN ISIMESCTVKCPLNTQTLGIGCTTTOVTTFEEVANAEKLVITDWDGVNH INI ISMGESCTVIVCPLNTOTLGIGCTTTDVTTFEEVANAEKLVITOWVDGNHICINI

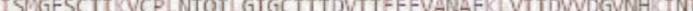

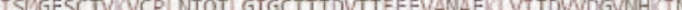
ISMGESCTVICVCPLNTOTLGIGCTTTDVTTFEEVANAEKLVITOWDGVNHICINI

Fig. 2. Multiple Sequence Alignment of G12 strains isolated in Chennai during 2016.

were considered untypable.

\section{Phylogenetic analysis}

MEGA5.0 software was used for phylogenetic analysis and amino acid similarity analysis was completed using BLAST algorithm and the tree was made by the neighbor joining method. MSA was conducted using Clustal Omega in order to identify the related genetic and amino acid arrangements of RVA.

\section{Nucleotide sequence accession numbers}

G12 along with $\mathrm{P}[6]$ and other strains of rotavirus nucleotide sequence isolated from Chennai and surrounding population was submitted to the GenBank with an accession number of KY774435 to KY774443.

\section{Results}

A total of 401 samples were collected for this study during the period January 2013 to December 2014. Out of the total 401 samples screened for RVA, 41.64\% (167/401) were positive for RVA by ELISA.

\section{Rotavirus genotypes}

Genotyping of RVA was completed for 167 samples. Out of the 167 samples, detection of both G and P types were found for 78 (46.67\%), $\mathrm{G}$ types alone were detected in $12(7.18 \%)$ and P types were detected only among $8(4.79 \%)$. Among the 167 positives five samples (2.99\%) were found to be G12P[6], followed by three G2G9P[4] and six G4P[6]P[11] types. Twelve $(12.18 \%)$ samples were untypable for both $G$ and $P$ types. In our study, where the $G$ and $\mathrm{P}$ combinations were concerned, G9P[4] was the predominant strain and the second predominant strain G2P[4] was frequently detected. Among other strains G1P[4], G4P[4], G3P[8], G9P[9], G9G4, G1P[8] was detected at significant frequency.

\section{Sequence and phylogenetic analysis}

Phylogenetic analysis for genetic relatedness (Fig. 1) was conducted and the results from multiple sequence alignment showed that our current isolated G12 strain was a single mutation in its amino acid residue where valine was replaced by leucine (Fig. 2). 


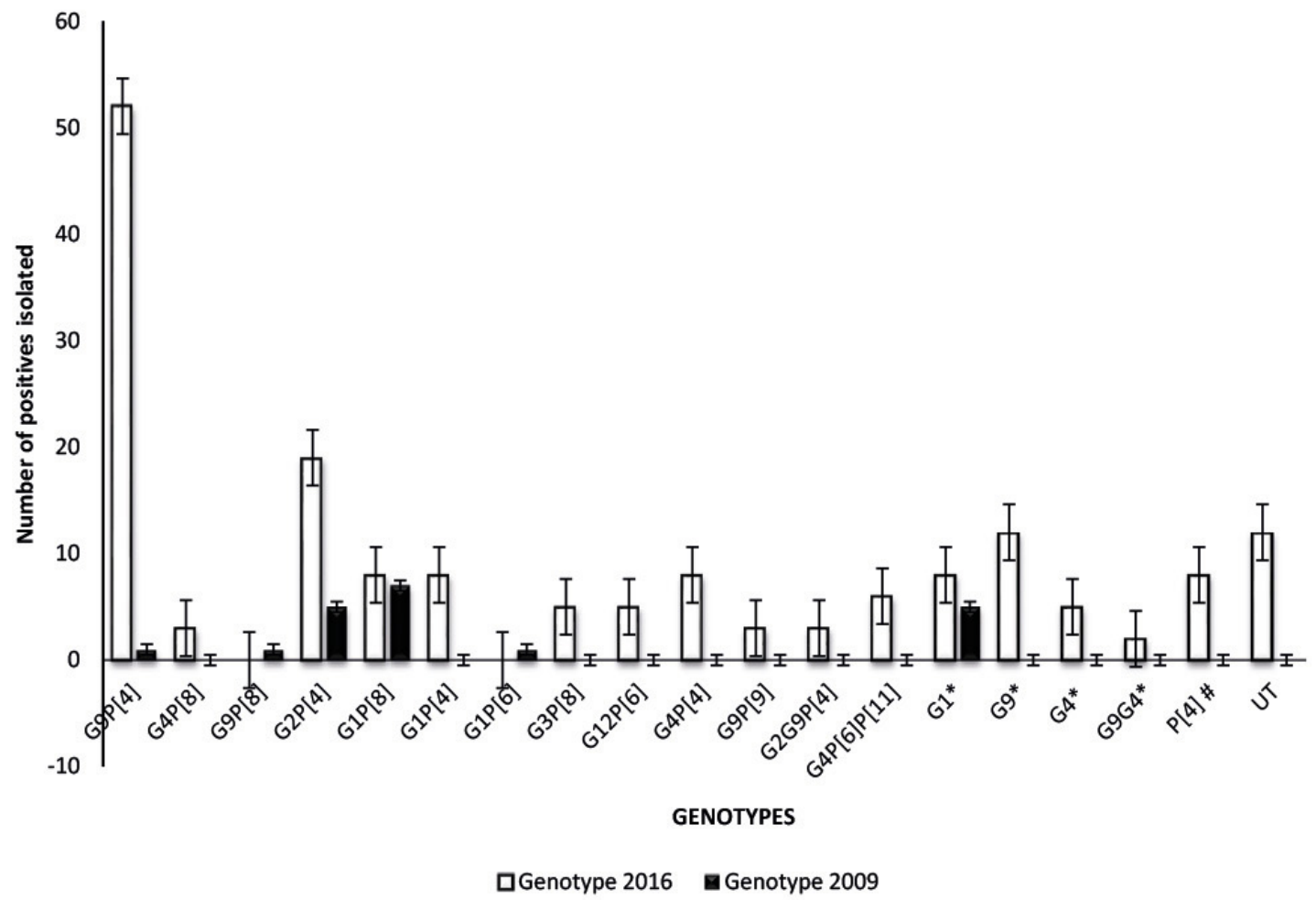

Fig. 3. Differences in strains isolated from Chennai.

\section{Discussion}

Human rotavirus A remains the leading cause of diarrheal deaths globally as well as in India. Even though a vaccine is available for this virus, India has only recently introduced the vaccine in UIP. This study was an attempt to determine the circulating rotaviral strains and to determine the strain diversity in and around Chennai, Tamilnadu-South India during the pre-vaccination era.

From different multicenter studies in India, $26 \%$ to $40 \%$ of infection is accounted for by RVA $^{22}$ and in this study RVA positivity was $46 \%$ which is considerably higher than the national average being $11.5 \%$ to $40 \%$, but there are countries that have reported $70 \%{ }^{23} \mathrm{RV}$ positive cases among acute watery diarrhea subjects.

Among $32 \mathrm{G}$ serotypes reported to date G1, G4, G9 and $25 \mathrm{P}$ serotypes $\mathrm{P}[4]$ and $\mathrm{P}[8]$ are predominant worldwide and contribute for $90 \%$ of infections in industrialized countries and about $68 \%$ infections in developing countries in south American and Asia.[8]12 P[6] genotype is rare in industrialized countries but has been found to be prevalent in the Asian population.
Since 1987, the G9 strain (found in pigs) has infected humans in most continents, suggesting a possible emergence of a fifth common $G$ type worldwide. ${ }^{24}$

RVA G2, one of the predominant genotype found in humans has been isolated in this study followed by G3 along with G4. This pattern of circulating genotypes is different from other parts of the country. ${ }^{25}$ Various studies from different parts of the world reported G9 to be the predominant genotype ${ }^{26}$ and in our study it was the predominant cause for gastroenteritis diarrhea followed by G2. Globally and in national dominance G1 is reported to be a predominant genotype where, as found in our study, this genotype is in few numbers and lesser than the average observed.

The uncommon G12 with P[6] genotype was identified in $5.43 \%$ of pediatrics who tested positive by RT-PCR from Chennai and its surrounding cities. This was detected during May to July 2015 and in June to August 2016. The incidence of infection with VP7 G12 genotypes in combination with VP4 types P[6] suggest the zoonotic transmission, probably 
acquired through close contact with animal rotavirus strain.

During our routine screening and in our previous studies ${ }^{19}$ we had not detected G12 (Fig. 3). But studies during June to September 2005 reported fourteen cases in combination with $\mathrm{P}[6]$ and $\mathrm{P}[8]$ and significant clustering of eight samples among the fourteen, represents a recent introduction of new rotavirus VP7ie., G12 genotype. ${ }^{27}$

Circulation of uncommon genotypes G10 and G12 has already been reported from Germany ${ }^{28,29,30}$ and reports show strong evidence that G10 belongs to bovine rotavirus strain, G10 being predominant among cattle population in Netherlands and reports say that interspecies transmission of group A rotavirus occurs between human and cattle. ${ }^{31,32}$

G12 strain has shown an increase in number with cases reported from the Argentinean population in combination with $\mathrm{P}$ [9], most of which resembled Asian population strains. ${ }^{33}$ From various studies conducted in $\mathrm{Nepal}^{34}$ and Bangladesh ${ }^{35}$ group A rotavirus genotype G12 has been reported to be G12 P[8] and G12 P[6]. During 2006 to 2007 yet another study from Bangladesh reported G12 genotype being $9.6 \%$ present among $39.5 \%$ of the positive cases tested. ${ }^{36}$

In the US, genotype G12 P[8] was detected at low frequencies during 2006 and during 2010 to 2011 and also predominantly showed diversified group of rotaviruses G12 P[8] and G12 P[6]. ${ }^{37}$ G12 rotavirus genotype was also reported from the European population and among these G12P[6] was present in two samples and mixed infection with G12G3P[8] was reported during 2009 which indicates the possibility of G12 strain emerging around the globe in support of our current study. 38

Indian studies conducted during 2010 from east India also reported circulation of G12P[6] for the first time in Manipur, contributing to $8 \%$ of the total samples tested. ${ }^{39}$ In the present study our observation for G12 along with P[6] tempts one to speculate that G12 strains are capable of spreading between humans (VP4 protein gene of $\mathrm{P}[6]$ which is uncommon in humans) and continuous surveillance is needed for mechanisms under which rotavirus reassortment and strain variability occurs.

\section{Sequence and phylogenetic analysis}

The G12 strains isolated from Chennai during the study were $98 \%$ and $97 \%$ identical with each other in nucleotide and amino acid level. We have compared our Chennai strain with 92 reference strains downloaded from NCBIBLAST and analysis of G12 strains revealed that all the strains belonged to sublineage 1 (Fig. 1). The Chennai strains showed similarities with Indian strains isolated from Kolkata during 2010 (KOL-2-10) and 2013 (BCK-2907). Interestingly, Chennai strains also clustered with foreign strains MRC-DPRU4090 from South Africa in 2011, A23 from Myanmar in 2011, VU-12-13-[136, 112, 150] from USA in 2013, ME659 from Italy in 2014, our strains showed high similarities with these foreign strains and to some extent close relationship with PAK-HF1 from Pakistan during 2010 and an Indian strain in 2005 from Kolkata.

From 92 strains randomly selected, 37 strains were analyzed for multiple sequence alignment which showed that there was an alteration in the valine amino acid sequences of the above said strains replaced by leucine and the outranged Pakistan and Kolkata strain has a replacement by methionine, (Fig. 2) which indicates that this conserved region may play a vital role for the mutagenic agent and understanding of the target region. Predicting the structure of this protein may help drug formulators to design vaccines in the post era of rotavirus in immunization schedule, thus creating a healthy India by reducing the IMR-U5 (infant mortality rate under 5). Rotavirus vaccine prevents 15 to $34 \%$ deaths in developing countries as well as 37 to $96 \%$ deaths in developed countries. ${ }^{39}$ Rotavirus vaccines are designed to meet the higher burden of the disease throughout the globe but has to be changed in view of the circulating strains, as the virus is capable of undergoing genetic reassortment.

The available vaccines in the market are Rotarix ${ }^{\circledR}$ (GlaxoSmithKline, Rixensart, Belgium) which is a monovalent rotavirus vaccine (RV1) created by attenuating a highly antigenic strain of human G1P[8] rotavirus. RotaTeq ${ }^{\circledR}$ (Merck and Co., Whitehouse Station, USA) which is a pentavalent vaccine (RV5) created by reassorting $G$ and $P$ antigens from human rotavirus, G1, G2, G3, G4 and P[1] with 
a bovine Rotavirus strain and is recommended for infants at 2,4 and 6 months of age. Rotavac ${ }^{\circledR}$ (Bharat Biotech, India) a naturally attenuated human neonatal strain containing one bovine segment $\{$ G9P [11]\} which was originally isolated from an asymptomatic infant at All India Institute of Medical Sciences (AIIMS) in 1988 and has been licensed in India by the World Health Organization in January 2014. ${ }^{40}$

To summarize, this study demonstrates that the high prevalence of RVA infection among children $\leq 5$ years of age and G9P[4] was observed as the predominant cause of RV diarrhea in this region. However, G2P[4] and G12P[6] were also detected in significant proportion. This reassures the importance that strains G9 in human rotavirus gastroenteritis along with emerging G12 genotypes warrants the need of including them in vaccine formulations.

Since the launch of an EQA programme in 2011 by WHO along with Global Reference Laboratory to control rotaviral infection, a circulation of new or uncommon strains clearly indicate the need of vaccine modifications periodically targeting the combination of all VP7 genotypes.

Zoonotic transmissions are likely to be relatively common events in India. Other than G5 strains, all $G$ types that have been reported in association with infections in humans globally are now found in India. This complex epidemiological data suggests the need for a unified protocol for the surveillance of Rotavirus by Indian laboratories.

More intensified investigation of animal rotavirus strains may identify the possible animal ancestor of the new genetic lineage. Continuous monitoring of human rotavirus strains circulating in local communities will be important to determine if we are again detecting the early stages of the global emergence of a novel genetic lineage of an "old" rotavirus serotype. This finding may have important implications for vaccine use in planned or already launched rotavirus immunization programs in numerous countries worldwide.

\section{REFERENCES}

1. Hyser JM, Estes MK. Rotavirus vaccines and pathogenesis: 2008. Curr Opin Gastroenterol 2009; 25: 36-43.
2. Vidhya P, Ponnambalam A, Gunasekeran P, Arunagiri K Sambasivam M, Krishnasami K. Rota virus infections: prevalence, diagnosis and prevention. Journal of Pediatric Sciences 2015; 7: e244

3. Banajeh SM, Abu-Asba BA. The epidemiology of all-cause and rotavirus acute gastroenteritis and the characteristics of rotavirus circulating strains before and after rotavirus vaccine introduction in Yemen: analysis of hospital-based surveillance data. BMC Infect Dis 2015; 15: 418.

4. Tate JE, Burton AH, Boschi-Pinto C, Parashar UD; World Health Organization-Coordinated Global Rotavirus Surveillance Network. Global, regional, and national estimates of rotavirus mortality in children < 5 years of age, 2000-2013. Clin Infect Dis 2016; 62(Suppl 2): S96-S105.

5. Molbak K, Fischer TK, Mikkelsen CS. The estimation of mortality due to rotavirus infections in sub-Saharan Africa. Vaccine 2000; 19: 393-395.

6. John J, Sarkar R, Muliyil J, Bhandari N, Bhan MK, Kang G. Rotavirus gastroenteritis in India, 2011-2013: revised estimates of disease burden and potential impact of vaccines. Vaccine 2014; 32(Suppl 1): A5-A9.

7. Das S, Varghese V, Chaudhury S, et al. Emergence of novel human group A rotavirus G12 strains in India. J Clin Microbiol 2003; 41: 2760-2762.

8. Santos N, Hoshino Y. Global distribution of rotavirus serotypes/ genotypes and its implication for the development and implementation of an effective rotavirus vaccine. Rev Med Virol 2005; 15: 29-56.

9. Shinozaki K, Okada M, Nagashima S, Kaiho I,Tanikuchi K. Characterization of human rotavirus strains with G12 and P[9] detected in Japan. J Med Virol 2004; 73: 612-616.

10. Ramani S, Banerjee I, Gladstone BP, et al. Geographic information systems and genotyping in identification of rotavirus G12 infections in residents of an urban slum with subsequent detection in hospitalized children: Emergence of G12 genotype in South India. J Clin Microbiol 2007; 45:432-437.

11. Fischer TK, Eugen-Olsen J, Pedersen AG, et al. Characterization of rotavirus strains in a danish population: High -frequency of mixed infections and diversity within the VP4 gene of P[8] strains. J Clin Microbiol 1104-1099:43 2005.

12. Gouvea V, Santos N. Rotavirus serotype G5: an emerging cause of epidemic childhood diarrhea. Vaccine 1999; 17: 1291-1292.

13. Fischer TK, Page NA, Griffin DD, et al. Characterization of incompletely typed rotavirus strains from GuineaBissau: identification of G8 and G9 types and a high frequency of mixed infections. Virology 2003; 311 : 125-133.

14. Jain V, Das BK, Bhan MK, Glass RI, Gentsch JR. Great diversity of group A rotavirus strains and high prevalence of mixed rotavirus infections in India. J Clin Microbiol 2001; 39: 3524-3529.

15. Castello A, Arguelles MH, Rota RP, et al. Molecular epidemiology of group A rotavirus diarrhea among children in Buenos Aires, Argentina, from 1999 to 2003 and emergence of the infrequent genotype G12. J Clin Microbiol 2006; 44: 2046-2050. 
16. Gentsch JR, Woods PA, Ramachandran M, et al. Review of $G$ and $P$ typing results from a global collection of rotavirus strains: implications for vaccine development. J Infect Dis 1996; 174 (Supp 1): S30-S36.

17. World Health Organization, Geneva, Switzerland. Readings on diarrhoea: Student manual.1992; ISBN 9241544449 .

18. Ye $\mathrm{XH}$, Jin $\mathrm{Y}$, Fang $\mathrm{ZY}$, et al. Etiological study on viral diarrhea among children in Lanzhou, Gansu, from 2004 through June 2005. Zhonghua Liu Xing Bing Xue Za Zhi 2006; 27: 117-122.

19. Mangayarkarasi V, Prema A, Gunasekaran P, Suresh Babu BV Kaveri K. A unique human rotavirus (non vaccine) G9P4 genotype infection in a child with gastroenteritis. Indian Pediatr 2012; 49: 569-571.

20. Gouvea V, Glass RI, Woods P, et al. Polymerase chain reaction amplification and typing of rotavirus nucleic acid from stool specimens. J Clin Microbiol 1990; 28: $276-282$.

21. Das BK, Gentsch JR, Cicirello HG, et al. Characterization of rotavirus strains from newborns in New Delhi, India. J Clin Microbiol 1994; 32: 1820-1822.

22. Babji S, Arumugam R, Sarvanabhavan A, et al. Multicenter surveillance of rotavirus diarrhea in hospitalized children $<5$ years of age in India, 2009-2012. Vaccine 2014; 11: A10-A12.

23. Broor S, Ghosh D, Mathur P. Molecular epidemiology of rotaviruses in India. Indian J Med Res 2003; 118: 59-67.

24. Desselberger U, Iturriza-Gomara M, Gray JJ. Rotavirus epidemiology and surveillance. Novartis Found Symp 2001; 238: 125-147.

25. Saluja T, Sharma SD, Gupta M, et al. A multicenter prospective hospital-based surveillance to estimate the burden of rotavirus gastroenteritis in children less than five years of age in India. Vaccine 2014; 32(Suppl 1): A13-A19.

26. Mullick S, Mandal P, Nayak MK, et al. Hospital based surveillance and genetic characterization of rotavirus strains in children ( $<5$ years) with acute gastroenteritis in Kolkata, India, revealed resurgence of G9 and G2 genotypes during 2011-2013. Vaccine 2014; 32(Suppl 1): A20-A28.

27. Ramani S, Banerjee I, Gladstone B, Gladstone BP, et al. Geographic Information Systems and Genotyping in Identification of Rotavirus in G12 Infections in Residents of an Urban Slum with Subsequent Detection Hospitalized Children: Emergence of G12 Genotype in South India. J Clin Microbiol 2007; 45: 432-437.

28. Marques AM, Diedrich S, Huth C, Schreier E. Group A rotavirus genotypes in Germany during 2005/2006. Arch Virol 2007; 152: 1743-1749.
29. Pietsch C, Liebert UG. Human infection with G12 rotaviruses, Germany. Emerg Infect Dis 2009; 15 1512-1515.

30. Steyer A, Poljsak-Prijatelj M, Bufon TL, Marcun-Varda $\mathrm{N}$, Marin J. Rotavirus genotypes in Slovenia: unexpected detection of G8P[8] and G12P[8] genotypes. J Med Virol 2007; 79: 626-632.

31. de Verdier Klingenberg K, Nilsson M, Swensson L. Rotavirus G-type restriction persistence and herd type specificity in Swedish cattle herds. Clin Diagn Lab Immunol 1999; 6: 181-185.

32. Rajendran P, Kang G. Molecular epidemiology of rotavirus in children and animals and characterization of an unusual G10P[15] strain associated with bovine diarrhea in south India. Vaccine 2014; 32: A89-A94.

33. Castello A, Arguelles MH, Rota RP, et al. Molecular epidemiology of Group A Rotavirus diarrhea among children in Buenos Aires, Argentina, from 1999 to 2003 and emergence of the infrequent genotype G12. J Clin Microbiol 2006; 44: 2046-2050.

34. Uchida R, Pandey BD, Sherchand JB, et al. Molecular epidemiology of rotavirus diarrhea among children and adults in Nepal: Detection of G12 strains with $\mathrm{P}[6]$ or P[8] and a G11P[25] strain. J Clin Microbiol 2006; 44: 3499-3505.

35. Rahman M, Sultana R, Ahmed G, et al. Prevalence of G2P [4] and G12P [6] rotavirus, Bangladesh. Emerg Infect Dis 2007; 13: 18-24.

36. Ahmed S, Hussain M, Akhter S, Islam T, Ahmed SU, Kabir ML. Genotypes of rotavirus diarrhoea in a children hospital of Bangladesh. Mymensingh Med J 2012; 21: 497-502.

37. Dennis AF, , D McDonald SM, Payne DC, et al Molecular epidemiology of contemporary G2P [4] human rotaviruses cocirculating in a single U.S. community: Footprints of a globally transitioning genotype. J Virol 2014; 88: 3789-3801.

38. Mukherjee A, Chattopadhyay S, Bagchi P, et al Surveillance and molecular characterization of rotavirus strains circulating in Manipur, North-Eastern India: Increasing prevalence of emerging G12 strains. Infect Genet Evol 2010; 10: 311-320.

39. Soares-Weiser K, Bergman H, Henschke N, Pitan F, Cunliffe N. Vaccines for preventing rotavirus diarrhoea: vaccines in use. Cochrane Database of Systematic Reviews 2019; 3: doi:10.1002/14651858.CD008521.

40. World Health Organization Global Advisory Committee on Vaccine Safety, 11-12 June 2014. Weekly Epidemiological Record 2014; 29: 325. 